The Agriculturists 18(1): 94-102(2020) ISSN 2304-7321 (Online), ISSN 1729-5211 (Print)

A Scientific Journal of Krishi Foundation

Indexed Journal

DOI: https://doi.org/10.3329/agric.v18i1.49462

\title{
Feasibility of Introducing Four Crops Based Cropping Patterns in Kushtia Area of Bangladesh
}

\author{
M. S. Rahman ${ }^{1}$, M. T. Islam ${ }^{2}$ and M. S. $\mathrm{Ali}^{3}$ \\ ${ }^{1}$ Pulses Research Centre and Regional Agricultural Research Station, Bangladesh Agricultural \\ Research Institute (BARI), Ishurdi, Pabna, Bangladesh; ${ }^{2}$ Pomology Division, Horticulture Research \\ Centre, BARI, Gazipur, Bangladesh; ${ }^{3}$ Regional Agricultural Research Station, BARI, Jashore, \\ Bangladesh.
}

*Corresponding author and Email: sayed_econ@yahoo.com

Received: 09 August 2019

Accepted: 25 June 2020

\begin{abstract}
The trial was conducted at Multi Location Testing (MLT) site under On-Farm Research Division, BARI, Kushtia during the last week of February, 2015 to second week of February, 2017 at farmers' field condition to find out the productivity and profitability of three alternate cropping patterns, i.e. $\mathrm{ACP}_{1}=$ Mustard (var: BARI Sarisha-15) - Mungbean (var: BARI Mung-6) - T. Aus rice (var: BRRI dhan48) - T. Aman rice (var: Binadhan-7), $\mathrm{ACP}_{2}=$ Lentil (var: BARI Masur-6) - Mungbean (var: BARI Mung-6) - T. Aus rice (var: BRRI dhan48) - T. Aman rice (var:Binadhan-7), $\mathrm{ACP}_{3}=$ Wheat (var: BARI Gom-28) - Mungbean (var: BARI Mung-6) - T. Aus rice (var: BRRI dhan48) - T. Aman rice (var:Binadhan-7) against the existing cropping pattern, i.e. ECP= Lentil (var: BARI Mashur-6) Sesame (BARI Teel-3) - T. Aman (var: Binadhan-7). Findings revealed that the required mean crop durations ranged 340-356 days for one cycle in a year in four crops based cropping patterns against 293 days in existing cropping pattern. Total seed/grain yields in terms of REY of $\mathrm{ACP}_{1}, \mathrm{ACP}_{2}$, and $\mathrm{ACP}_{3}$ were $14.85,16.06$ and $14.92 \mathrm{t} \mathrm{ha}^{-1}$ year $^{-1}$, respectively which were $44 \%, 56 \%$ and $45 \%$, respectively higher than that of existing pattern $\left(10.30 \mathrm{t} \mathrm{ha}^{-1}\right.$ year-1). Mean production efficiency (32.53-40.43 $\mathrm{kg} \mathrm{ha}^{-1} \mathrm{day}^{-1}$ ), land use efficiency (93.15-97.53\%) and mean gross margin ( Tk. 109393 Tk. $127834 \mathrm{ha}^{-1}$ ) of all alternate cropping patterns were higher than that of existing cropping pattern (PE: $23.63 \mathrm{~kg} \mathrm{ha}^{-1} \mathrm{day}^{-1}$, LUE: $80.28 \%$ and gross margin Tk. $94929 \mathrm{ha}^{-1}$ ). As a result, all alternate cropping patterns were agronomically feasible and economically profitable. Among the alternate cropping patterns, $\mathrm{ACP}_{2}=$ Lentil (var: BARI Masur-6) - Mungbean (var: BARI Mung-6) - T. Aus rice (var: BRRI dhan48) - T. Aman rice (var: Binadhan-7) performed the best. Therefore, farmers in Kushtia area of Bangladesh might follow the alternate cropping patterns in high and medium high land for higher crop productivity and profitability over existing cropping pattern.
\end{abstract}

Keywords: Four crops, grain yield, production efficiency, rice equvalent yield, profitability

\section{Introduction}

Bangladesh is the most densely populated (about 1033 persons per sq. $\mathrm{km}$ ) country in the world with a population of 161.40 million, which is increasing annually at the rate of about $1.10 \%$
(Bangladesh Population, 2018). By the year 2030, the population will increase to about 186 million (United Nations, 2017). At present total cultivable land of the country is 8.44 million hectares and it is shrinking day by day. Demographic pressure and increased 
urbanization have caused cultivated area to decline at a rate of $1 \%$ per year. There is very little scope of increasing cultivable land but there are some scopes of increasing cropping intensity (192\%) by improving the existing cropping patterns through inclusion of short duration crops viz., mustard, potato, mungbean and T. Aus rice in the rice based cropping system (Mondal et al., 2015).

The south western part (Kushtia, Meherpur, Chuadanga, Jhenaidah and Jashore districts) is located under Agro Ecological Zone (AEZ) 11 and 12. The soil is calcareous under High Ganges River Floodplain. About $76 \%$ lands are under high and medium high land which has a great potential to produce four crops in a piece of land in a year. The cropping intensity of this area ranges $260-264 \%$ and about $93 \%$ lands are under irrigation (DAE, 2016). Farmers in these areas have a great potential to conduct four crops in a same piece of land in a year because $76 \%$ lands are under high and medium high land and 93\% lands are under irrigation. But, no attempt has been made for development of four crops based improved cropping patterns in these areas.

Mondal et al. (2015) reported that T. Aman rice (var: Binadhan-7) - Mustard (var:BARI Sarisha15) -Mungbean (var:BARI Mung-6) -T. Aus rice (var: Parija) cropping pattern gave higher benefit with reasonable cost of production and could be easily fitted in the existing pattern. Hossain et al. (2014) also reported that T. Aman rice (var. Binadhan-7) - Mustard (var.BARI Sarisha-15) Mungbean (var.BARI Mung-6) - T. Aus rice (var. Parija) are agronomically feasible and economically profitable compared to the existing pattern. Due to growing of four crops in a year in the same piece of land more employment opportunity could be created and at the same time due to increased production of crops, food and nutritional security could be ascertained for the farmers and at the same time cropping intensity and productivity could be increased (Mondal et al., 2015; Hossain et al., 2014). Four crops based alternate cropping patterns LentilMungbean-T. Aus rice-T. Aman rice in Faridpur region (Ahmed et al., 2019), Lentil-Mungbean$\mathrm{T}$. Aus rice-T. Aman rice in high barind tract Rajshahi (Hossain et al., 2018), Potato-Boro- T. Aus-T. Aman in Cumilla region (Hossain et al., 2018) and Potato - Mungbean - Jute - T. Aman rice at Domar, Nilphamari (Chowdhury et al., 2017) are agronomically feasible and economically profitable. With this view, the present study was, therefore, undertaken to find out the productivity and profitability of alternate cropping patterns and to compare its productivity, profitability, land use efficiency, and production efficiency against farmer's existing cropping pattern.

\section{Materials and Methods}

The study was conducted at Multi Location Testing (MLT) site under On-Farm Research Division (OFRD), BARI, Kushtia during the last week of February, 2015 to first week of March, 2017 at farmers' field condition. Soil samples were taken separately over $0-15 \mathrm{~cm}$ depth to determine baseline and post soil properties, respectively. Three four-crop based alternate cropping patterns $(\mathrm{ACP})$, i.e., $\mathrm{ACP}_{1}=$ Mustard (var. BARI Sarisha-15) - Mungbean (var. BARI Mung-6) - T. Aus rice (var. BRRI dhan48) - T. Aman rice (var. Binadhan-7), $\mathrm{ACP}_{2}=$ Lentil (var. BARI Masur-6) - Mungbean (var. BARI Mung6) - T. Aus rice (var. BRRI dhan48) - T. Aman rice (var. Binadhan-7), $\mathrm{ACP}_{3}=$ Wheat (var. BARI Gom-28) - Mungbean (var. BARI Mung6) - T. Aus rice (var. BRRI dhan48) - T. Aman rice (var. Binadhan-7) and one existing cropping pattern (ECP); Lentil (var. BARI Masur-6) Sesame (var. BARI Till-3) - T. Aman rice (var. Binadhan-7) as control were tested as per objectives.

The experiment was laid out in block approach where four blocks were separated and each block was consisted in one hectare of land for each cropping pattern including 7-8 farmers. The first block was mustard based ACP, second block lentil based ACP and third block wheat based ACP and fourth block existing cropping pattern based which was considered as control. The trial 
was started by mungbean cultivation as first crops in all alternate cropping patterns. Lentil, sesame, mustard, wheat and mungbean seed was sown in broadcasting method due to minimize labour cost of farmers. Fertilizer management and intercultural operations like weeding, mulching, irrigation and pest management were done according to Mondal et al. (2011), Azad et al., (2014) and BRRI (2013) for studied crops. The fertilizer dose for studied crops was lentil (Farmers dose: 17.15-18.7-5-0-0-0 for NPKSZnB kgha ${ }^{-1}$ and Experiment dose: 20 - 17 17.5 - 9.44 -1-1 for NPKSZnB kgha ${ }^{-1}$ ), sesame (86.5-18-26-9.5-0-0 for NPKSZnB $\mathrm{kgha}^{-1}$ ), mustard (126-35-46-29.5-2.5-2.12 for NPKSZnB $\left.\mathrm{kgha}^{-1}\right)$, wheat $(20-17-17.5-9.44-1-1$ for NPKSZnB kgha-1), mungbean (17-17-18-10-0-1 for NPKSZnB kgha-1), T. Aman (Farmer dose: 103.4-22.5-37.5-9.5-2.6 for NPKSZnB kgha-1 and Experiment dose: 86-22.5-37.5-9.5-1.61-0 for NPKSZnB $\mathrm{kgha}^{-1}$ ) and T. Aus (86-22.5-37.59.5-2.15-0.6 for NPKSZnB kgha ${ }^{-1}$ ).

Mugbean (var: BARI Mung-6) seed was sown in broadcasting method during 26 February-7 March and harvested during 01-11May in all ACPs (Table 2).After two picking of the pods, the entire green biomass $\left(1.22-1.40\right.$ tha $\left.^{-1}\right)$ was ploughed down into soil and left for decomposition until the T. Aus was transplanted. In mungbean, Tafgor $(2 \mathrm{ml} / \mathrm{L})$ and Imitaf $20 \mathrm{SL}$ $(0.5 \mathrm{ml} / \mathrm{L})$ were sprayed for controlling aphid and thrips, respectively.

T. Aus rice seedlings were grown in adjacent plot and transplanting was done with 24-25 days old seedling of rice var. BRRI dhan 48 at a spacing $20 \mathrm{~cm} \mathrm{X} 15 \mathrm{~cm}$ during 12-15 May for all ACPs. T. Aus rice was harvested during 06-08 August for all ACPs in two consecutive years. T. Aman rice seedlings were also grown in adjacent plot and transplanting was done with 27-28 days old seedling of rice var. Binadhan-7 for all cropping patterns at a spacing $20 \mathrm{~cm} \mathrm{X} 15 \mathrm{~cm}$ during 09-12 August for all ACPs and 02-08 August for ECP. T. Aman rice was harvested during 06-12 November for all ACPs and 04-07 November for ECP in two consecutive years.
Mustard (var: BARI Sarisha-15) seed was sown in broadcasting method during 12-15 November and harvested during 07-10 February in $\mathrm{ACP}_{1}$. In mustard, Rovral-50 WP @ 2 g/L was sprayed at early stage for controlling alternaria blight disease.

Lentil (var: BARI Masur-6) seed was sown in broadcasting method during 09-10 November in $\mathrm{ACP}_{2}$ and 15-18 November for ECP. Lentil was harvested on 26 February in $\mathrm{ACP}_{2}$ and 03-07 March for ECP. In lentil, foot and root rot as well as stemphylium blight were observed in some plots. Provex-200 WP@ 3 g/L and Rovral50 wp@ $2 \mathrm{~g} / \mathrm{L}$ were sprayed at early stage for controlling these diseases.

Wheat (var: BARI Gom-28) seed was sown in broadcasting method during 16-17 November and harvested on 04 March in $\mathrm{ACP}_{3}$. Sesame (var: BARI Til-3) seed was sown in broadcasting method during 15-18March and harvested during 11-14 June in ECP.

All field operations and management practices of both alternate and existing cropping patterns were closely monitored and the data were recorded for observing agro-economic performance. The yield data of product and byproduct were recorded. Grain/seed and straw yields of all rice, mustard, lentil, wheat, sesame and mungbean as well as price data of all inputs and outputs were taken accordingly.

Agronomic performance viz., land use efficiency, production efficiency and rice equivalent yield of cropping patterns were calculated.

\subsection{Land use efficiency}

It is worked out by taking total duration of individual crop in a pattern divided by 365 days as Tomer and Tiwari (1990) as follows:

Land use efficiency $=\frac{\sum \text { di }}{365} \times 100$

Where, di $=$ duration of the $\mathrm{i}^{\text {th }}$ crop $\mathrm{i}=1,2,3$ and 4 


\subsection{Production efficiency}

Production efficiency in terms of $\mathrm{Kg} \mathrm{ha}^{-1} \mathrm{day}^{-1}$ was calculated by total production in a cropping pattern divided by total duration of crops in that pattern (Tomer and Tiwari, 1990).

Where,

$$
\text { Production efficiency }=\frac{\sum Y i}{\sum d i}
$$

$Y i=$ Yield of the $i^{\text {th }}$ crop

$\mathrm{di}=$ duration of the $\mathrm{i}^{\text {th }}$ crop

$\mathrm{i}=1,2,3$ and 4

\subsection{Rice equivalent yield}

For comparison between cropping patterns, the yield of all crops was converted into rice equivalent yield (REY) on the basis of prevailing market price of individual crop (Verma and Modgal, 1983).

Rice equivalent yield $\left(\mathrm{t} \mathrm{ha}^{-1}\right)$

Yield of individual crop $\times$ Market price of that crop Market price of rice

\subsection{Economic analysis}

The economic indices like total variable cost and gross return were also calculated on the basis of prevailing market price of the produces. For economic evaluation of four tested cropping patterns, average data of two crop cycles were used. Gross return was calculated on the basis of taka per hectare of product and by-product. Total variable cost (TVC) of different crops was calculated on the basis of taka per hectare of different operations performed and materials used for raising the crops. The MBCR of the existing cropping pattern and any replacement for it can be computed as the marginal value product ((MVP) over the marginal value cost (MVC). The Marginal of prevalent pattern (F) and any potential replacement (E) for it was computed as (CIMMYT, 1988).

Marginal Benefit Cost Ratio (MBCR) = $\frac{\text { Gross return (B) }- \text { Gross return (F) }}{\text { TVC (B) }- \text { TVC (P) }}=\frac{\text { MVP }}{\text { MVC }}$

\section{Results and Discussion}

\subsection{Changes in soil properties}

The result of nutrient status of initial and post soil was presented in Table 1. Initially, the soil was slightly alkaline (7.8-8.1), medium in organic matter and $\mathrm{K}$ content. The contents of $\mathrm{S}$ and $\mathrm{B}$ were also in medium level. Total N, P and $\mathrm{Zn}$ contents were found low in mustard, lentil and wheat based four crops plot. After completion of two cycles, result revealed that the mean $\mathrm{pH}$ was slightly lower than initial value in all plots whereas OM, K, total N, P, S, Zn and B increased in lentil based four crops plot due to incorporation of mungbean in the soil and cultivation of lentil. The contents of $\mathrm{K}, \mathrm{Zn}$ and B increased while OM, $\mathrm{P}$ and $\mathrm{S}$ decreased in mustard based four crops based plot. Total $\mathrm{N}$ was same in post and initial soil. In wheat based four crops plot, the contents of $\mathrm{K}$, total $\mathrm{N}, \mathrm{P}, \mathrm{Zn}$ and $\mathrm{B}$ increased due to incorporation of mungbean in the soil but $\mathrm{OM}$ and $\mathrm{S}$ decreased in post soil than initial soil. These results were supported by the findings of Mondal et al. (2015), Chowdhury et al. (2017), Hossain et al. (2018) and Ahmed et al.(2019).

\subsection{Crop management}

Crop management practices of the cropping patterns are shown in Table 2. The average crop (field) duration of $\mathrm{ACP}_{1}, \mathrm{ACP}_{2}$ and $\mathrm{ACP}_{3}$ took 340, 356 and 352 days, respectively while, existing cropping pattern required 293 days. Turnaround times in four crops based improved cropping patterns of $\mathrm{ACP}_{1}, \mathrm{ACP}_{2}$ and $\mathrm{ACP}_{3}$ were 25,09 and 13 days, respectively whereas it was 72 days in existing cropping pattern. All alternate cropping patterns were successfully accommodated in a year. Similar findings were cited by Ahmed et al.(2019), Hossain et al. (2018), Hossain et al.(2018), Chowdhury et al.(2017) and Mondal et al.(2015). 
Table 1. Chemical properties of soil (0-15 cm depth) of the experimental field at Kushtia Sadar, Kushtia during the experimental period

\begin{tabular}{|c|c|c|c|c|c|c|c|c|}
\hline \multirow{2}{*}{$\begin{array}{l}\text { Cropping pattern } \\
\text { based plot }\end{array}$} & \multirow[t]{3}{*}{$\mathrm{pH}$} & \multirow{2}{*}{$\begin{array}{c}\text { Organic } \\
\text { matter } \\
(\%)\end{array}$} & \multirow{2}{*}{ 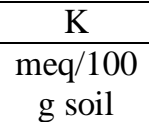 } & \multirow{2}{*}{$\begin{array}{l}\text { Total } \\
\mathrm{N} \\
(\%)\end{array}$} & $\mathrm{P}$ & $S$ & $\mathrm{Zn}$ & $\mathrm{B}$ \\
\hline & & & & & \multicolumn{4}{|c|}{$\mu \mathrm{g} \mathrm{g}^{-1}$} \\
\hline \multicolumn{8}{|l|}{ Initial (2015) } & \\
\hline Mustard based CP & 7.8 & 2.17 & 0.24 & 0.11 & 11.70 & 20.40 & 0.87 & 0.47 \\
\hline Lentil based CP & 8.1 & 1.97 & 0.27 & 0.10 & 10.70 & 18.21 & 0.87 & 0.41 \\
\hline Wheat based CP & 7.9 & 1.92 & 0.28 & 0.09 & 8.80 & 18.40 & 0.72 & 0.54 \\
\hline Critical limit & - & - & 0.12 & 0.12 & 10.00 & 10.00 & 0.60 & 0.20 \\
\hline Interpretation & Slightly Alkaline & Medium & Medium & Low & Low & Medium & Low & Medium \\
\hline \multicolumn{9}{|l|}{ Post (2017) } \\
\hline Mustard based CP & 7.7 & 1.92 & 0.25 & 0.11 & 11.45 & 18.24 & 0.95 & 0.58 \\
\hline Lentil based CP & 7.2 & 2.28 & 0.29 & 0.11 & 11.25 & 20.48 & 0.92 & 0.58 \\
\hline Wheat based CP & 7.8 & 1.87 & 0.32 & 0.10 & 9.17 & 16.57 & 0.85 & 0.58 \\
\hline Critical limit & - & - & 0.12 & 0.12 & 10.00 & 10.00 & 0.60 & 0.20 \\
\hline Interpretation & Slightly Alkaline & Medium & Medium & Low & Low & Medium & Low & Mediun \\
\hline
\end{tabular}

\subsection{Seed/Grain yield}

The mean seed/grain yield of mustard, mungbean, T. Aus and T. Aman for $\mathrm{ACP}_{1}$ were $1.35,1.14,5.10$ and $4.59 \mathrm{t} \mathrm{ha}^{-1}$, respectively (Table 2). In case of $\mathrm{ACP}_{2}$ the mean seed/grain yield of lentil, mungbean, T. Aus and T. Aman were $1.37,0.81,4.99$ and $4.42 \mathrm{t} \mathrm{ha}^{-1}$, respectively. The mean seed/grain yield of wheat, mungbean, T. Aus and T. Aman for $\mathrm{ACP}_{3}$ were $3.90,0.80,4.97$ and $4.57 \mathrm{t} \mathrm{ha}^{-1}$, respectively while in ECP lentil, sesame and T. Aman were $0.78,1.25$ and $4.90 \mathrm{tha}^{-1}$, respectively. The yield of $\mathrm{T}$. Aus rice was found satisfactory in all improved pattern, which might be due to residual effect of mungbean stover. The mean straw/stover yield of mustard, mungbean, T. Aus and T. Aman for $\mathrm{ACP}_{1}$ were 1.96, 1.23, 4.02 and $4.07 \mathrm{t} \mathrm{ha}^{-1}$, respectively while mean straw/stover yield of lentil, mungbean, T. Aus and T. Aman for $\mathrm{ACP}_{2}$ were 1.51, 1.40, 4.10 and $4.01 \mathrm{t} \mathrm{ha}^{-1}$, respectively. The mean straw/stover yield of wheat, mungbean, T. Aus and T. Aman for $\mathrm{ACP}_{3}$ were $2.93,1.31,3.96$ and $4.06 \mathrm{t} \mathrm{ha}^{-1}$, respectively while in ECP lentil, sesame and T. Aman were $1.11,2.23$ and $4.12 \mathrm{t} \mathrm{ha}^{-1}$, respectively. The yield of all crops showed similar trend in two consecutive years. Similar findings were found by Ahmed et al. (2019), Hossain et al. (2018),
Hossain et al.(2018), Chowdhury et al.(2017), Mondal et al. (2015) and Hossain et al. (2014).

\subsection{Rice equivalent yield}

Total productivity of different cropping systems was evaluated in terms of rice equivalent yield (REY) and it was calculated from the yield of component crops. REYs varied due to different cropping systems (Table 3). The mean REY of $\mathrm{ACP}_{1}, \mathrm{ACP}_{2}, \mathrm{ACP}_{3}$ and ECP were 14.85, 16.06, 14.92 and 10.30 tha $^{-1}$ year $^{-1}$, respectively. The highest REY (16.06 tha ${ }^{-1}$ year $^{-1}$ ) was calculated at $\mathrm{ACP}_{2}$ and it was followed by $\mathrm{ACP}_{3}$ (14.92 tha ${ }^{1}$ year $^{-1}$ ) and $\mathrm{ACP}_{1}$ (14.85 tha $^{-1}$ year $\left.^{-1}\right)$. Similar trends were found in two consecutive years except $\mathrm{ACP}_{2} 2^{\text {nd }}$ cycle. The lowest $\mathrm{REY}$ was found in ECP (10.30 tha $^{-1}$ year $\left.^{-1}\right)$. REY of $\mathrm{ACP}_{1}$, $\mathrm{ACP}_{2}, \mathrm{ACP}_{3}$ was $44 \%, 56 \%$ and $45 \%$ higher over ECP (10.30 tha $^{-1}$ year $\left.^{-1}\right)$. Higher rice equivalent yield was obtained in improved cropping pattern due to inclusion of new crops and varieties. It was evident from the above findings that alternate cropping patterns provided higher yield compared to existing pattern. This finding was supported by Ahmed et al. (2019), Hossain et al. (2018), Hossain et al. (2018), Chowdhury et al. (2017), Nazrul et al. (2017), Mondal et al. (2015), Hossain et al. (2014); and Nazrul et al. (2013). 


\subsection{Land use efficiency}

Land use efficiency is the effective use of land in a cropping year, which mostly depends on crop duration. The mean land use efficiency of $\mathrm{ACP}_{1}$, $\mathrm{ACP}_{2}, \mathrm{ACP}_{3}$ and ECP were 93.15, 97.53, 96.44 and $80.28 \%$, respectively (Table 3 ). The highest land use efficiency (97.53\%) was found in $\mathrm{ACP}_{2}$ and it was followed by $\mathrm{ACP}_{3}(96.44 \%)$ and $\mathrm{ACP}_{1}(93.15 \%)$. Similar trends were found in two consecutive years. The lowest land use efficiency was found in ECP (80.28\%). The land use efficiency was higher in alternate cropping patterns due to cultivation of more component crops in these patterns. The similar trend of the findings was cited by Chowdhury et al. (2017), Nazrul et al. (2017) and Nazrul et al. (2013).

\subsection{Production efficiency}

Maximum production efficiency was obtained from alternate cropping patterns over existing cropping pattern (Table 3). The higher production efficiency of alternate cropping patterns might be due to inclusion of four crops and new modern varieties as well as improved management practices. The mean production efficiency of $\mathrm{ACP}_{1}, \mathrm{ACP}_{2}, \mathrm{ACP}_{3}$ and $\mathrm{ECP}$ were found to be $35.78,32.53,40.43$ and $23.63 \mathrm{~kg} \mathrm{ha}^{-1}$ day $^{-1}$, respectively which were $51 \%, 38 \%$ and $71 \%$ higher over existing cropping pattern (23.63 $\mathrm{kg} \mathrm{ha}^{-1}$ day $\left.^{-1}\right)$. Results revealed that maximum production efficiency $(40.43 \%)$ was found in $\mathrm{ACP}_{3}$ and it was followed by $\mathrm{ACP}_{1}(35.78 \%)$ and $\mathrm{ACP}_{2}(32.53 \%)$. The lowest production efficiency was found in ECP $(23.63 \%)$.

The same trend was observed in two consecutive years. Similar findings were cited by Ahmed et al. (2019), Chowdhury et al. (2017), Nazrul et al. (2017), Nazrul et al. (2013) and Khan et al. (2005) in case of improved cropping patterns.

\subsection{Economic analysis}

In terms of economic analysis, gross return, total variable cost and gross margin of system productivity of four cropping sequences differed among the cropping patterns. The mean gross return of $\mathrm{ACP}_{1}, \mathrm{ACP}_{2}, \mathrm{ACP}_{3}$ and $\mathrm{ECP}$ were calculated at Tk. 284030, Tk. 304977, Tk.
288864 and Tk. 200966 ha $^{-1}$, respectively while the mean total variable cost of $\mathrm{ACP}_{1}, \mathrm{ACP}_{2}$, $\mathrm{ACP}_{3}$ and ECP were found to be Tk. 174638, Tk. 177143, Tk. 178263 and Tk. $106037 \mathrm{ha}^{-1}$, respectively (Table 3 ). As a result, the mean gross margin of $\mathrm{ACP}_{1}, \mathrm{ACP}_{2}, \mathrm{ACP}_{3}$ and $\mathrm{ECP}$ were calculated at Tk. 109393, Tk. 127834, Tk. 110601 and Tk. 94929 ha $^{-1}$, respectively which were $15 \%, 35 \%$ and $17 \%$ higher over existing cropping pattern.

The higher returns from alternate cropping patterns might be due to inclusion of new crops and high yielding varieties. Results revealed that the highest mean gross margin (Tk. $127834 \mathrm{ha}^{-1}$ ) was found in $\mathrm{ACP}_{2}$ due to inclusion of high value crop lentil and it was followed by $\mathrm{ACP}_{3}$ (Tk. $110601 \mathrm{ha}^{-1}$ ) and $\mathrm{ACP}_{1}$ (Tk. $\left.109393 \mathrm{ha}^{-1}\right)$. The lowest mean gross margin was found in ECP (Tk. $94929 \mathrm{ha}^{-1}$ ). According to cycles, the highest gross margin (Tk. $111855 \mathrm{ha}^{-1}$ ) was found in $\mathrm{ACP}_{2}$ and it was followed by ECP (Tk. $80719 \mathrm{ha}^{-1}$ ), $\mathrm{ACP}_{1}$ (Tk. $77444 \mathrm{ha}^{-1}$ ) and $\mathrm{ACP}_{3}$ (Tk. $58569 \mathrm{ha}^{-1}$ ) in $1^{\text {st }}$ cycle while in $2^{\text {nd }}$ cycle, the highest gross margin (Tk. $162634 \mathrm{ha}^{-1}$ ) was found in $\mathrm{ACP}_{3}$ and it was followed by $\mathrm{ACP}_{2}$ (Tk. $\left.143813 \mathrm{ha}^{-1}\right), \mathrm{ACP}_{1}$ (Tk $141341 \mathrm{ha}^{-1}$ ) and ECP (Tk. $109139 \mathrm{ha}^{-1}$ ). The trend differed due to variation of yield and market prices in two consecutive years. The highest mean MBCR was found in $\mathrm{ACP}_{2}$ (1.47) and it was followed by $\mathrm{ACP}_{3}$ (1.24) and $\mathrm{ACP}_{1}$ (1.21).

Similar findings were cited by Ahmed et al. (2019), Hossain et al. (2018), Hossain et al. (2018), Chowdhury et al.(2017), Nazrul et al. (2017), Nazrul et al. (2013) and Khan et al. (2005) in case of improved cropping patterns. The profitability analysis showed that inclusion of mustard, mungbean, lentil, wheat and T. Aus in the existing cropping pattern showed higher benefit. Among the alternate cropping patterns, $\mathrm{ACP}_{2}$ (Lentil-Mungbean-T. Aus-T. Aman) was found the best for higher benefit. The gross return of $2^{\text {nd }}$ cycle in all cropping patterns was higher due to higher market price of rice compared to $1^{\text {st }}$ cycle. As a result, gross margin and MBCR were higher in $2^{\text {nd }}$ cycle. 
Table 2. Performance of different crops under existing and alternate cropping patterns during 2015-2017 at Kushtia Sadar, Kushtia

\begin{tabular}{|c|c|c|c|c|c|c|c|c|c|c|c|c|c|c|c|c|}
\hline \multirow{2}{*}{$\begin{array}{l}\text { Parameters } \\
\text { Crop }\end{array}$} & \multirow{2}{*}{ Cycle } & \multicolumn{3}{|c|}{$\begin{array}{l}\text { Existing Cropping } \\
\text { Pattern (ECP) }\end{array}$} & \multicolumn{4}{|c|}{ Alternate $\mathrm{Cr}$} & \multicolumn{4}{|c|}{$\begin{array}{c}\text { Alternate Cropping Pattern } 2 \\
\left(\mathrm{ACP}_{2}\right)\end{array}$} & \multicolumn{4}{|c|}{$\begin{array}{c}\text { Alternate Cropping Pattern } 3 \\
\left(\mathrm{ACP}_{3}\right)\end{array}$} \\
\hline & & Lentil & $\begin{array}{l}\text { Sesa- } \\
\text { me }\end{array}$ & $\begin{array}{c}\mathrm{T} . \\
\text { Aman }\end{array}$ & $\begin{array}{l}\text { Must- } \\
\text { ard }\end{array}$ & $\begin{array}{l}\text { Mung- } \\
\text { bean }\end{array}$ & T. Aus & $\begin{array}{c}\mathrm{T} . \\
\text { Aman }\end{array}$ & Lentil & $\begin{array}{l}\text { Mung- } \\
\text { bean }\end{array}$ & T. Aus & $\begin{array}{c}\text { T. } \\
\text { Aman }\end{array}$ & Wheat & $\begin{array}{l}\text { Mung } \\
\text {-bean }\end{array}$ & $\begin{array}{c}\text { T. } \\
\text { Aus }\end{array}$ & $\begin{array}{c}\text { T. } \\
\text { Aman }\end{array}$ \\
\hline & & BARI & BARI & BINA & BARI & BARI & BRRI & BINA & BARI & BARI & BRRI & BINA & BARI & BARI & BRRI & BINA \\
\hline Variety & & Masur-6 & Til-3 & dhan-7 & $\begin{array}{l}\text { Sarisha- } \\
15\end{array}$ & Mung-6 & dhan 48 & dhan-7 & Masur-6 & Mung-6 & dhan 48 & dhan-7 & Gom-28 & Mung-6 & dhan 48 & dhan-7 \\
\hline \multirow{4}{*}{$\begin{array}{l}\text { Date of } \\
\text { transplanting/ } \\
\text { sowing }\end{array}$} & $1^{\mathrm{st}}$ & $\begin{array}{l}18 / 11 / \\
15\end{array}$ & $\begin{array}{c}18 / 3 / \\
15\end{array}$ & $\begin{array}{c}2 / 8 / 1 \\
5\end{array}$ & $\begin{array}{c}15 / 11 / \\
15\end{array}$ & $\begin{array}{l}27-28 \\
/ 02 / 15\end{array}$ & $\begin{array}{r}13-14 \\
/ 05 / 15\end{array}$ & $\begin{array}{r}10-12 \\
/ 08 / 15\end{array}$ & $\begin{array}{l}09 / 11 / \\
15\end{array}$ & $\begin{array}{c}01 / 03 / \\
15\end{array}$ & $\begin{array}{c}14 / 05 / 1 \\
5\end{array}$ & $\begin{array}{c}09 / 08 / \\
15\end{array}$ & $\begin{array}{c}17 / 11 / \\
15\end{array}$ & $\begin{array}{c}07 / 03 / \\
15\end{array}$ & $\begin{array}{c}14 / 05 / \\
15\end{array}$ & $\begin{array}{c}10 / 08 / \\
15\end{array}$ \\
\hline & $2^{\text {nd }}$ & $15 / 11 /$ & $15 / 03$ & $04 / 08$ & $12-14$ & 28 & $12-14$ & $10-12$ & $10 / 11 /$ & 01/03/ & 14 & 09/08/ & $16 / 11 /$ & 07/03/ & $15 / 05 /$ & $11 / 08 /$ \\
\hline & & 16 & $/ 16$ & $/ 16$ & $/ 11 / 16$ & $/ 02 / 16$ & $/ 05 / 16$ & $/ 08 / 16$ & 16 & 16 & $/ 5 / 16$ & 16 & 16 & 16 & 16 & 16 \\
\hline & $1^{\mathrm{st}}$ & 03/03/ & $11 / 06$ & $07 / 11$ & $07-09 /$ & $01-10 /$ & $06-08 /$ & $11-12$ & $26 / 02 /$ & $10 / 05 /$ & $06 / 08 /$ & $06 / 11 /$ & 04/03/ & $10 / 05 /$ & 06/08/ & $11 / 11 /$ \\
\hline \multirow{3}{*}{$\begin{array}{l}\text { Date of } \\
\text { harvesting }\end{array}$} & & 16 & $/ 15$ & $/ 15$ & $02 / 16$ & $05 / 15$ & $08 / 15$ & $/ 11 / 15$ & 16 & 15 & 15 & 15 & 16 & 15 & 15 & 15 \\
\hline & $2^{\text {nd }}$ & 06/03/ & $14 / 06$ & $04 / 11$ & $08-10$ & 01-08 & $06-08$ & $11-12$ & $26 / 02 /$ & $11 / 05 /$ & 06/08/ & $06 / 11 /$ & 04/03/ & $10 / 05 /$ & 07/08/ & $11 / 11 /$ \\
\hline & & 17 & $/ 16$ & $/ 16$ & $/ 02 / 17$ & $/ 05 / 16$ & $/ 08 / 16$ & $/ 11 / 16$ & 17 & 16 & 16 & 16 & 17 & 16 & 16 & 16 \\
\hline \multirow{3}{*}{$\begin{array}{l}\text { Field duration } \\
\text { (days) }\end{array}$} & $1^{\mathrm{st}}$ & 106 & 86 & 98 & 86 & 73 & 86 & 94 & 110 & 71 & 85 & 90 & 108 & 65 & 85 & 94 \\
\hline & $2^{\text {nd }}$ & 111 & 92 & 93 & 89 & 72 & 87 & 93 & 109 & 72 & 85 & 90 & 109 & 65 & 85 & 93 \\
\hline & Total & & 293 & & \multicolumn{4}{|c|}{340} & \multicolumn{4}{|c|}{356} & \multicolumn{4}{|c|}{352} \\
\hline \multirow{3}{*}{$\begin{array}{l}\text { Turn around } \\
\text { time }\end{array}$} & $1^{\mathrm{st}}$ & 10 & 14 & 51 & 18 & 2 & 4 & 2 & 02 & 03 & 02 & 02 & 02 & 03 & 03 & 05 \\
\hline & $2^{\text {nd }}$ & 10 & 9 & 50 & 17 & 3 & 3 & 2 & 02 & 02 & 02 & 03 & 02 & 04 & 03 & 04 \\
\hline & Total & & 72 & & \multicolumn{4}{|c|}{25} & \multicolumn{4}{|c|}{09} & \multicolumn{4}{|c|}{13} \\
\hline \multirow{4}{*}{$\begin{array}{l}\text { Seed/Grain } \\
\text { yield }\left(\mathrm{t} \mathrm{ha}^{-1}\right)\end{array}$} & $1^{\mathrm{st}}$ & 0.75 & 1.20 & 4.70 & 1.20 & 1.15 & 4.97 & 4.59 & 1.21 & 0.81 & 4.93 & 4.49 & 3.49 & 0.78 & 4.88 & 4.46 \\
\hline & $2^{\text {nd }}$ & 0.80 & 1.30 & 5.10 & 1.49 & 1.12 & 5.22 & 4.59 & 1.52 & 0.81 & 5.05 & 4.34 & 4.31 & 0.81 & 5.05 & 4.68 \\
\hline & Mean & 0.78 & 1.25 & 4.90 & 1.35 & 1.14 & 5.10 & 4.59 & 1.37 & 0.81 & 4.99 & 4.42 & 3.90 & 0.80 & 4.97 & 4.57 \\
\hline & $1^{\mathrm{st}}$ & 1.10 & 2.30 & 4.20 & 2.00 & 1.24 & 4.16 & 4.12 & 1.65 & 1.40 & 4.25 & 4.07 & 2.86 & 1.22 & 3.93 & 4.10 \\
\hline \multirow{2}{*}{$\begin{array}{l}\text { Stover/straw } \\
\text { yield }\left(\mathrm{t} \mathrm{ha}^{-1}\right)\end{array}$} & $2^{\text {nd }}$ & 1.11 & 2.15 & 4.03 & 1.92 & 1.22 & 3.88 & 4.02 & 1.37 & 1.40 & 3.95 & 3.94 & 2.99 & 1.40 & 3.98 & 4.02 \\
\hline & Mean & 1.11 & 2.23 & 4.12 & 1.96 & 1.23 & 4.02 & 4.07 & 1.51 & 1.40 & 4.10 & 4.01 & 2.93 & 1.31 & 3.96 & 4.06 \\
\hline
\end{tabular}


Table 3. Economic performance of existing and alternate cropping patterns at Kushtia Sadar, Kushtia during 2015-17

\begin{tabular}{|c|c|c|c|c|c|}
\hline Parameters & Cycle & ECP & $\mathrm{ACP}_{1}$ & $\mathrm{ACP}_{2}$ & $\mathrm{ACP}_{3}$ \\
\hline \multirow{3}{*}{ Rice equivalent yield $\left(\mathrm{t} \mathrm{ha}^{-1}\right)$} & $1^{\mathrm{st}}$ & 11.03 & 15.15 & 16.98 & 14.45 \\
\hline & $2^{\text {nd }}$ & 9.57 & 14.55 & 15.14 & 15.39 \\
\hline & Mean & 10.30 & 14.85 & 16.06 & 14.92 \\
\hline \multirow{3}{*}{ Land use efficiency (\%) } & $1^{\mathrm{st}}$ & 79.45 & 92.88 & 97.53 & 96.44 \\
\hline & $2^{\text {nd }}$ & 81.10 & 93.42 & 97.53 & 96.44 \\
\hline & Mean & 80.28 & 93.15 & 97.53 & 96.44 \\
\hline \multirow{3}{*}{$\begin{array}{l}\text { Production efficiency } \\
\text { (kg/ha/day) }\end{array}$} & $1^{\text {st }}$ & 22.93 & 35.13 & 32.13 & 38.66 \\
\hline & $2^{\text {nd }}$ & 24.32 & 36.42 & 32.92 & 42.19 \\
\hline & Mean & 23.63 & 35.78 & 32.53 & 40.43 \\
\hline \multirow{3}{*}{ Gross return $\left(\mathrm{Tk} . \mathrm{ha}^{-1}\right)$} & $1^{\mathrm{st}}$ & 188197 & 252619 & 282649 & 240994 \\
\hline & $2^{\text {nd }}$ & 213734 & 315441 & 327305 & 336734 \\
\hline & Mean & 200966 & 284030 & 304977 & 288864 \\
\hline \multirow{3}{*}{$\begin{array}{l}\text { Total variable cost } \\
\left(\mathrm{Tk} . \mathrm{ha}^{-1}\right)\end{array}$} & $1^{\text {st }}$ & 107478 & 175175 & 170794 & 182425 \\
\hline & $2^{\text {nd }}$ & 104595 & 174100 & 183492 & 174100 \\
\hline & Mean & 106037 & 174638 & 177143 & 178263 \\
\hline \multirow{3}{*}{ Gross margin $\left(\mathrm{Tk} \mathrm{ha}^{-1}\right)$} & $1^{\mathrm{st}}$ & 80719 & 77444 & 111855 & 58569 \\
\hline & $2^{\text {nd }}$ & 109139 & 141341 & 143813 & 162634 \\
\hline & Mean & 94929 & 109393 & 127834 & 110601 \\
\hline \multirow{3}{*}{ MBCR } & $1^{\mathrm{st}}$ & & 0.95 & 1.49 & 0.70 \\
\hline & $2^{\text {nd }}$ & & 1.46 & 1.44 & 1.77 \\
\hline & Mean & & 1.21 & 1.47 & 1.24 \\
\hline
\end{tabular}

Unit price 2015-2016: lentil: Tk. 85/kg; Sesame: Tk. 30/kg; T. Aman: Tk. 15.75/kg; Mustard: Tk. 46.50/kg; Mungbean: Tk. 47.50/kg; T.Aus: Tk. 11.25/kg; and wheat: Tk. 18.75/kg.

Unit price 2016-17: lentil: Tk. 65/kg; Sesame: Tk. 30.50/kg; T. Aman: Tk. 20.50/kg; Mustard: Tk. 42.50/kg; Mungbean: Tk. 50/kg; T. Aus: Tk. 16.25/kg; and wheat: Tk. 22.50/kg.

\section{Conclusions}

The above findings showed that all alternate cropping patterns were superior to existing cropping pattern in terms of seed/grain yield, REY, production efficiency, land use efficiency and profitability. It could be easily fitted in the existing cropping pattern within a year. Soil chemical analysis revealed that organic matter, $\mathrm{N}, \mathrm{Zn}$ and $\mathrm{B}$ content increased due to incorporation of mungbean in the soil of alternate cropping pattern. Among the alternate cropping patterns, $\mathrm{ACP}_{2}=$ Lentil (var: BARI Masur-6) - Mungbean (var: BARI Mung-6) T.Aus rice (var: BRRI dhan48) - T. Aman rice (var: Binadhan-7) was the best. The cropping intensity and productivity could be increased by growing four crops in a year in the same piece of land. So, the farmers in Kushtia area of Bangladesh might follow these alternate patterns in their high and medium high land for higher productivity and profitability.

\section{References}

Ahmed S., Quddus FMR., Mohiuddin M., Islam MR., Hossain MA. 2019. Performance of lentil-mungbean-t.aus rice- $T$. aman rice against existing cropping pattern lentiljute- T. aman rice in Faridpur region. Bangladesh Journal of Agricultural Research, 44(3): 537-552. 
Azad MAK., Haider M Raisul, Naim Zulkar. 2014. Leaflet, Agam paka aman dhaner ufshi zat, Binadhan-7. Bangladesh Institute of Nuclear Agriculture (BINA), BAU campus, Mymensingh.

Bangladesh Population. 2018. Google. Bangladesh population, dated 30.06.2020. https://www.google.com/search?q=bangla desh+population\&oq=bangladesh+populat ion\&aqs $=$ chrome.0.018.47429j0j7\&source $\mathrm{id}=$ chrome $\& \mathrm{ie}=\mathrm{UTF}-8$

Bangladesh Rice Research Institute (BRRI). 2013. Modern rice cultivation, 17th Edition. Gazipur 1701, Bangladesh, 1-80 pp.

Chowdhury AK., Zahan T., Anowar MM., Islam MK., Molla SH., Khan ASMM. Rahman. 2017. Improvement of potato-jute-t.aman cropping pattern through inclusion of mungbean. Bangladesh Agronomy Journal, 20(2): 87-95.

Department of Agriculture Extension (DAE). 2016. Annual Report 2015-16, Kushtia. Report presented in the regional research and extension program review and planning workshop 2016 held during 2426 May 2016 at RARS, BARI, Jashore.

Hossain I., Mondal MRI., Islam MJ., Aziz MA., Khan ASMMR., Begum F. 2014. Four crops based cropping pattern studies for increasing cropping intensity and productivity in Rajshahi region of Bangladesh. Bangladesh Agronomy Journal, 17(2): 55-60.

Hossain MH., Bhowal SK., Bashir MM., Khan ASMMR. 2018. Productivity and profitability of four crops based cropping pattern in Cumilla region of Bangladesh. The Agriculturists, 16(2): 88-92.

Hossain MS., Alam SMM., Abida MY., Hasan MK., Khan ASMMR. 2018. Productivity and nutrient balance of lentil-mungbean T. aus - T. aman rice cropping pattern in high barind tract. Bangladesh Agronomy Journal, 21(1): 105-115.

International Maize and Wheat Improvement Center (CIMMYT). 1988. From agronomic data to farmer recommendations: an economic training manual. CIMMYT, Mexico, D. F. 79 p.

Khan MAH., Quayyum MA., Nazrul MI., Sultana N., Mollah MRA. 2005. On-farm evaluation of production potential and economics of mustard-rice based improved cropping system. Journal of Socioeconomic Research \& Development, 2(1): 37-42.

Mondal RI., Begum F., Aziz A., Sharif SH. 2015. Crop sequences for increasing cropping intensity and productivity. SAARC Journal of Agriculture, 13(1):135147.

Mondal RI., Islam MS., Bhuiyan MAJ., Rahman MM., Alam MS., Rahman MHH. 2011. Edited. KRISHI PROJUKTI HATBOI (Handbook of Agro-technology), $5^{\text {th }}$ edition, Bangladesh Agricultural Research Institute, Gazipur 1701, Bangladesh, 196206 pp.

Nazrul MI., Hasan MK., Mondal MRI. 2017. Production potential and economics of mungbean in rice based cropping pattern in Sylhet region under AEZ 20. Bangladesh Journal of Agricultural Research, 42(3): 413-424.

Nazrul MI., Shaheb MR., Khan MAH.,Khan ASMMR. 2013. On-farm evaluation of production potential and economic returns of Potato-Rice Based improved cropping system. Bangladesh Journal of Agricultural Research, 16(2): 41-50.

Tomer SS., Tiwari AS. 1990. Production potential and economics of different crop sequences. Indian Journal of Agronomy, 35(1\&2): 30-35.

United Nations. 2017. United Nations, Department of Economic and Social Affairs, Population Division. World Population Prospects: The 2017 Revision. New York.

Verma SP., Modgal SC. 1983. Production potential and economics of fertilizer application as resources constraints in maize, wheat crop sequence. Himachal Journal of Agricultural Research, 9(2): 89-92. 